\title{
Retorica política de la inmigración educativa en Cataluña (España) y realidad del aula*
}

\section{Núria Llevot Calvet}

Universidad de Lleida (Spain), Dipartamento de Pedagogía

doi: 10.7358/ecps-2013-008-llev

nllevot@pip.udl.cat

\section{EDUCATIONAL IMMIGRATION POLICY IN CATALONIA (SPAIN) AND CLASSROOM REALITY}

\section{Abstract}

There has been a notable evolution in immigration over the last ten years, with obvious effects on the education system. This increase, mainly concentrated in the public sector, has been a serious challenge for the administration and schools. Despite efforts made in the design of policies, contingency plans and allocation of resources, the results can still be improved. In Catalonia, after an observation period, the emphasis has been placed on organising the various levels of administration to carry out an efficient intervention. In practice, regarding foreign students, this has meant adopting compensatory policies focused on social cohesion and multiculturalism. This article is a review of educational policies in Catalonia, with a specific analysis of the multicultural practices applied to education in a primary school. This article is part of a report on immigration policies on education, with examples of schools that apply intercultural communication in four regions of Spain (see Martinez Usarralde, 2010).

Keywords: Catalonia, Immigration, Multiculturalism, School, Social cohesion.

* Este artículo forma parte de un estudio sobre las políticas educativas de inmigración con ejemplos de escuelas que practican la interculturalidad en cuatro Comunidades Autónomas españolas (ver Martínez Usarralde, 2010). 
La evolución de la inmigración ha sido notable en los últimos diez años y su efecto en el sistema educativo es manifiesto. Este aumento, y su mayor concentración en la red pública, ha supuesto un desafío muy importante para la Administración y los centros escolares de muchos países (Lippke \& Schulz, 2012). En España pesar de los esfuerzos realizados en el diseño de políticas, planes de intervención y dotación de recursos, los resultados son aún mejorables (Llevot \& Garreta, 2012).

En Cataluña, después de una etapa de observación ${ }^{1}$ del fenómeno, se ha puesto el énfasis en la organización de los diferentes niveles de la Administración para realizar una intervención eficiente. En la práctica, y por lo que respecta al alumnado extranjero, esto ha supuesto, en primer lugar, la adopción de políticas compensatorias y de multiculturalidad ${ }^{2}$ para, recientemente, centrar el interés en la idea de la cohesión social y la interculturalidad.

Nuestro artículo realiza un repaso de las políticas educativas en Cataluña para concretarse y analizar las prácticas interculturales en un centro de primaria.

\section{EVOLUCIÓN DEL ALUMNADO DE ORIGEN INMIGRANTE EN CATAluña ${ }^{3}$}

El incremento de alumnado de origen extranjero en las aulas de Cataluńa no sólo ha sido numérico sino que también se ha ampliado de forma notable el número de países de los que procede $\mathrm{y}$, en consecuencia, su diversidad cultural y lingüística.

A continuación mostraremos un gráfico en el que se observa la evolución del alumnado extranjero en los centros privados-concertados y en los públicos, de Primaria, en Cataluña desde el curso 1999/2000 hasta el

1 Todos los estudios de investigación sobre el fenómeno migratorio en las comarcas catalanas se encuentran en la página internet del Observatorio Permanente de la Inmigración (OPI). Esta web (http://www.opi.udl.cat/opi/; http://www.opi.udl.cat/opi/) fue creada en enero de 2011 por el grupo de investigación "Análisis social y educativo", del que forma parte la autora del artículo, de la Universidad de Lleida.

2 El comparativista García Garrido (2004) profundiza en las diferencias entre el multiculturalismo, de cuño americano, más descriptivo, pragmático y sociológico y el interculturalismo, de origen europeo, más prescriptivo, creativo y pedagógico.

3 Según CIDE (2010) el 1 de enero de 2009 en Cataluña había 179 nacionalidades diferentes, entre las cuales destaca la marroquina (225.244 personas empadronadas), que supone una quinta parte de la población extranjera total. También son muy numerosas las nacionalidades rumana (96.448), ecuatoriana (82.261) y boliviana (58.323). 
2009/2010. La dinámica que se ha seguido para la distribución del alumnado de origen extranjero (los criterios más comunes han sido: el lugar de residencia o la existencia de vacantes en el centro escolar) ha comportado que los extranjeros estén más presentes en la red pública que en la privada, así como en unos centros más que en otros. Podemos observar, asimismo, cómo esta situación se ha ido intensificando a lo largo de los años (Figura 1).

Además, las últimas cifras recogidas del Departament d'Educació (2010) indican que los alumnos de Primaria y de Secundaria Obligatoria originarios de América del Sur y de América Central son los más numerosos (26.281 y 20.902 respectivamente) seguidos de los del Magreb (16.085 y 9.373), especialmente Marruecos. Por otro lado, el colectivo procedente de América del Norte es el menos numeroso (182 y 125).

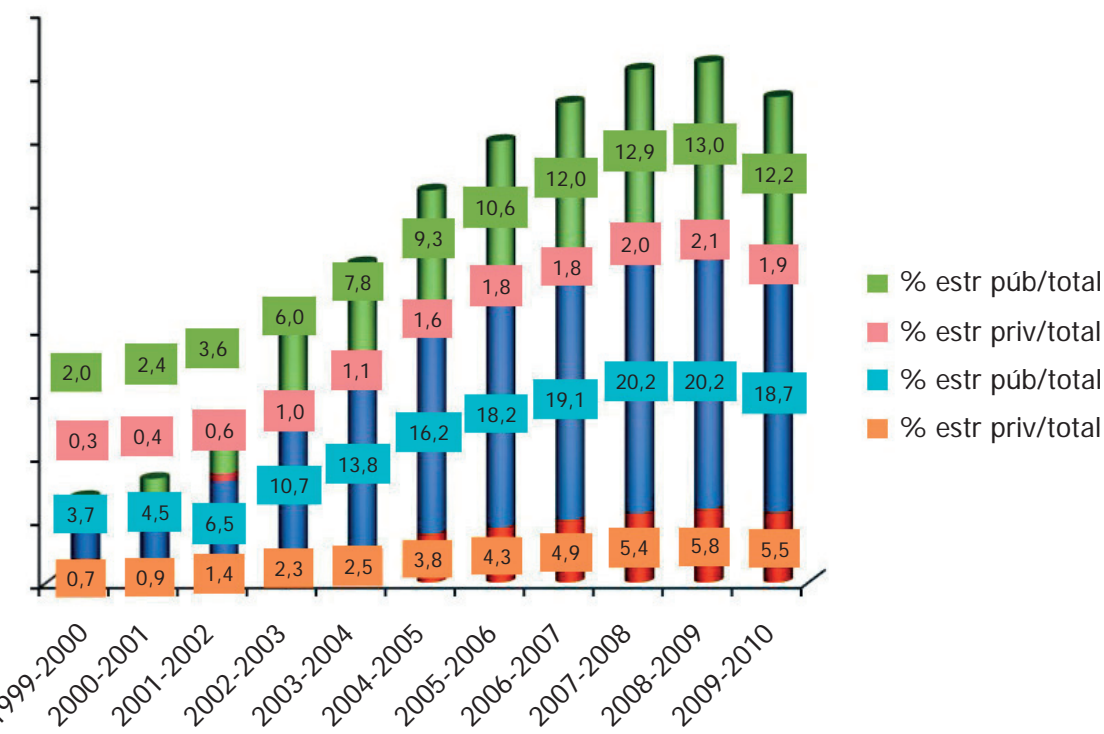

Fuente: Departament d'Educació. Servei d'Indicadors i Estadística. Estadística de l'Educació (http:// www.20.gencat.cat/portal/site/Educacio).

Figura 1. - Evolución de los alumnos extranjeros de Primaria, sector público y privado-concertado. 


\section{PolíticA EDUCATIVA DIRIGIDA A NIÑOS Y NIÑAS INMIGRANTES}

\subsection{Organismos responsables en Cataluña}

Desde que a principios de 1981 se transfirieron las competencias de educación en Cataluña a la Generalitat, se inició el camino de la estructura organizativa actual. Y aunque años atrás se desarrolló, como presentaremos, el Programa de Educación Compensatoria, actualmente la intervención con alumnado extranjero está en manos de la Direcció General d'Innovació y, concretamente, de la Subdirecció General de Llengua i Cohesió Social (http://www.xtec.cat/lic; http://www.xtec.cat/lic), que es la responsable de las actuaciones y que dirige los equipos de trabajo de Llengua i Cohesió Social (LIC). Concretamente, la citada Subdirección tiene las funciones de: facilitar criterios y elementos de reflexión para conseguir una escuela abierta, solidaria y de calidad para todo el alumnado en el marco de la sociedad catalana y ante los retos de la inmigración; consolidar la lengua catalana como lengua vehicular de la enseńanza y de la comunicación en los centros educativos y como eje vertebrador del proyecto educativo en un marco plurilingüe; impulsar y planificar programas y actuaciones para el desarrollo de la educación intercultural, basada en el conocimiento de la cultura propia y de las otras culturas, y el respeto a la diferencia y a los valores cívicos y democráticos en un marco de buena convivencia; elaborar criterios y promover actuaciones para fomentar la inclusión escolar y garantizar la igualdad de oportunidades de todo el alumnado y prevenir cualquier tipo de marginación; promover actuaciones que permitan el trabajo en el entorno escolar y otras actuaciones transversales, mediante el fomento de la colaboración y la coordinación entre todos los agentes implicados en la educación; aportar criterios para la formación continua del profesorado, de los equipos directivos o de los profesionales de apoyo a los centros en lo referente a la didáctica y al uso de la lengua, la educación intercultural y la cohesión social; impulsar la elaboración, selección y difusión de materiales específicos; realizar estudios e investigaciones sobre lengua, interculturalidad y cohesión social en el marco de los procedimientos generales de evaluación del Departament d'Educació; e impulsar y promover actuaciones que faciliten la colaboración y coordinación en el ámbito de la enseñanza de la lengua.

Las ideas anteriores se han llevado a la práctica con la elaboración de planes de acogida de integración de todo el alumnado en los centros, la elaboración del proyecto lingüístico de centro, el desarrollo de la educación intercultural (potenciando la conciencia de igualdad entre el alumnado, el conocimiento de las diferentes culturas presentes en los centros y la cultura 
del diálogo y la convivencia), la creación de aulas de acogida y de Talleres de Adaptación Escolar (TAE) y la potenciación de planes de entorno ${ }^{4}$, y la formación de los profesionales de los centros que cuentan con aulas de acogida.

\subsection{Legislación e impacto de los cambios politicos}

Desde que, con el Partido Socialista Obrero Español (PSOE) y Convergència i Unió $(\mathrm{CiU})$ en el gobierno de España y Cataluña respectivamente, a finales de 1990 se firmó un convenio por el que el Ministerio de Educación de España cedía la gestión del Programa de Educación Compensatoria ${ }^{5}$ al Departament d'Ensenyament de la Generalitat con el objetivo de prestar apoyo a la plena integración del alumnado con problemática de marginación social, desde Cataluña se fueron tomando las riendas de lo que sería la política educativa dirigida al alumnado extranjero.

Este programa de educación compensatoria, poco a poco fue derivando su atención, que llegaría a ser exclusiva, hacia la población escolar gitana y de origen inmigrado (Llevot, 2005; Garreta, 2006). Posteriormente fue apareciendo el discurso intercultural, que iría impregnando levemente el programa hasta su desaparición y posterior creación y desarrollo del plan LIC y sus equipos de trabajo.

En 1992 el Departament d'Ensenyament, al definir el currículum de la educación primaria (Departament d'Ensenyament, 1992a) y secundaria obligatoria (Departament d'Ensenyament, 1992b), ya hace referencia a «la interculturalidad». El Departament creía necesario que las innumerables decisiones que diariamente se tomaban fueran coherentes con un proyecto educativo tendente a una sociedad intercultural - sin definirla - que fomentara la capacidad de relación interpersonal y la de inserción y actuación social. Pero es en el año 1993 cuando se da un hecho que desembocará, años después, en la concreción de la apuesta intercultural: la aprobación del Plan Interdepartamental d'Immigració (Departament de Benestar Social, 1993); documento que preveía actuaciones del Departament d'Ensenyament, además de otros departamentos, en el campo de la interculturalidad, concretamente en la formación de formadores. Por otro lado, uno de los motivos del desarrollo del discurso intercultural en Cataluña es el notable incremento del alumnado

4 Como una red de apoyo a la comunidad educativa con la colaboración de los diferentes servicios y recursos municipales y de otras instituciones o entidades de ámbito social, cultural y deportivo del territorio.

5 Programa que desde 1981 se centraba en luchar contra la desigualdad socioeconómica, geográfica y por motivos culturales. 
de origen extranjero en las aulas, especialmente en los centros públicos, y la influencia de la Unión Europea, ya que a lo largo de los cursos 1993/1994 y 1995/1996 se harían públicas diversas orientaciones y resoluciones del Consejo de la Unión Europea sobre la respuesta a los problemas del racismo y la xenofobia. Pero, en la práctica, la respuesta dada por la Administración catalana a la diversidad cultural en la escuela fue mantener prácticamente intacto el currículum oficial y limitar la práctica pedagógica de los maestros a las líneas curriculares que impone la institución escolar, que es unicultural y uniforme, tanto si entre el alumnado hay presencia de minorías como si no (Pascual, 1992). Eso sí, debe tenerse en cuenta la aportación del Programa de Educación Compensatoria, que funcionaba, aunque con limitaciones, desde hacía años; las diversas experiencias - fruto de la creciente sensibilidad hacia las diferencias culturales -; los cursos de formación en este tema y el apoyo de movimientos, asociaciones e instituciones diversas, los convenios y apoyos de carácter internacional, y los materiales y recursos que se elaboraban para ser utilizados por el profesorado (Bartolomé, 1997; Llevot, 2005).

Será con la publicación del Eix transversal sobre educació intercultural, en 1996, cuando se realice una apuesta más clara para avanzar hacia este modelo. En este documento (Departament d'Ensenyament, 1996) se afirma que la educación ha de preparar a las nuevas generaciones para la vida en la sociedad catalana, finalidad que implica desarrollar en todos los alumnos un conjunto de actitudes y aptitudes respecto a la cultura propia y la diversidad cultural existente en la sociedad y en la escuela: arraigo en la propia comunidad; apertura, respeto y diálogo; tolerancia y sentido crítico; convivencia y superación constructiva de los conflictos; empatía y afirmación de la propia identidad, etc. En este marco se invita al profesorado a introducir en las escuelas estos planteamientos y a no verlos como una sobrecarga que genera problemas y estrés añadida a la tarea docente. La educación intercultural se define para todo el alumnado con el objetivo de lograr la citada "competencia cultural» y para todos los centros y aulas.

La comprensión del discurso intercultural era difícil ya que se debían articular las prácticas anteriores, esencialmente asimiladoras, y los cambios que suponía la traducción a la praxis del discurso intercultural (Palaudàrias, 1998). Esto comportó, entre otras cosas, que el profesorado promoviera pocas prácticas y orientaciones nuevas y realmente interculturales y que cuando lo hacía entrara en la dinamización de acciones escolares en torno a las "otras culturas» sin demasiada reflexión previa, cayendo a menudo en el folklorismo - lo que Banks (1986) denominaba adición. Los docentes, en los que descansaba la materialización del discurso, estaban poco o mal formados, eran en gran parte resistentes al discurso intercultural y su desarrollo, y creían que era una cuestión de los centros con este problema, que representaba una 
sobrecarga de trabajo en una ya de por sí compleja realidad escolar (Garreta, 2003). Es decir, aquellos que tienen el problema y no huyen del mismo buscan soluciones que otros quieren copiar (lo que ahora llamamos «buenas prácticas»).

El año 2004, con un gobierno tripartito de izquierdas ${ }^{6}$, dentro de la lógica de pensamiento de lo que sería poco después el Pla de Ciutadania i Immigració 2005-08, se creó el Plan de Lengua y Cohesión Social ${ }^{7}$, que supuso la desaparición del programa de educación compensatoria, y el curso 2004/2005 inició su camino con la creación de los equipos LIC, que serían los máximos representantes del cambio en el ámbito educativo. El documento pivota sobre la idea de cohesión social que articulará la dirección tomada por la Generalitat a partir de esta fecha y afirma que dicha cohesión debe surgir del reconocimiento de la pluralidad existente, de la voluntad de construir vínculos de solidaridad y del fomento de la convivencia ciudadana según los valores democráticos. En este marco, la educación intercultural se plantea como necesaria para todos los centros (insistiendo en que no se trata de una educación enfocada a la diversidad cultural entendida como inmigración, como así constaba en documentos anteriores que otorgaban poca relevancia a los gitanos ${ }^{8} \mathrm{y}$ a las lenguas minoritarias de modo que sus casos los trataban en los anexos) y debe impregnar el currículum para preparar a un alumnado que vive en una sociedad culturalmente diversa. El documento sigue atribuyendo una elevada responsabilidad a los docentes y, aunque desde un punto de vista organizativo (designación de un coordinador lingüístico de interculturalidad y cohesión social en cada centro, así como un tutor de acogida en los centros que tienen aula de acogida) va más allá, deja excesivamente abiertas las directrices respecto a la forma de actuar. Los docentes deberán formarse para adecuar sus competencias actuales a la nueva realidad y, aunque es cierto que la formación inicial va mejorando, actualmente los docentes aún están limitados para desarrollar su trabajo cotidiano.

Dada esta situación, se pusieron en marcha a partir del citado Pla de Llengua i Cohesió Social los llamados planes educativos de entorno, la potenciación y difusión de buenas prácticas, la mejora de la formación de los docentes, la mejora de la acogida en los centros escolares (se habla del «centro acogedor»), etc. Además, el Departament d'Educació realizó a principios de

6 Partit Socialista de Catalunya, Esquerra Republicana de Catalunya e Iniciativa per Catalunya-Verds.

7 http://www.xtec.cat/lic/documents.htm.

8 Fruto de la investigación INCLUD-ED, Strategies for social inclusion and cohesion from Education (2006-2011), sobre fracaso, barreras y experiencias positivas con la población gitana recientemente se ha publicado un estudio (ver Crea, 2010). 
2008 una polémica propuesta: la creación de un sistema de acogida inmediata en espacios transitorios para el alumnado que llegaba una vez iniciado el curso escolar. Esta propuesta, que se puso en marcha durante el curso 2008/2009 en dos poblaciones catalanas con elevada presencia de población de origen extranjero (Reus y Vic), pretendía intensificar la atención global al citado alumnado y a sus familias y complementar las aulas de acogida con la creación de centros en los que se ubicara el alumnado extranjero que fuera llegando, el cual recibiría clases de catalán y castellano, hábitos sociales, derechos y deberes, etc. La temporalidad de la estancia en estos centros es la cuestión más importante pero la menos concretada (aunque pocas cuestiones relacionadas con esta nueva propuesta lo han sido) y, a pesar de que se plantea de forma temporal, diferentes voces (como SOS Racismo, una parte de los especialistas en educación de las universidades catalanas y los socios de gobierno) afirman que se trata de una medida segregadora y que puede alargarse en el tiempo dada la situación existente en determinados centros y aulas.

La presión en las aulas, incluidas las de acogida, es constatada por el profesorado, que recibe un número importante de alumnado de origen inmigrado y esto le ha llevado a optar por la segregación temporal del alumnado recién llegado. Sin afirmar que la segregación pueda llegar a ser de larga duración o permanente, ya que no se ha realizado un análisis en profundidad de su desarrollo, lo cierto es que tampoco la segregación de corta duración parece ser lo adecuado para incorporar a este alumnado, ya que dilata la inserción normalizada (eso sí, descongestiona temporalmente la situación) y siempre existe el temor de que se alargue este proceso en aras de un futuro beneficio. Parece que la tendencia actual, ante las resistencias y dificultades para trabajar con un número importante de alumnado de origen inmigrado de múltiples procedencias y que llegan a los centros y aulas en diferentes momentos del curso y de su escolarización, preconiza el regreso a las prácticas segregacionistas temporales, como las realizadas con los gitanos años atrás (ver Secretariado Nacional Gitano, 1982; Garreta, 2003 y 2009). Los trabajos recientes que hemos realizado (en Demba \& Garreta, 2012) y otros que citado anteriormente indican que hay otras formas de gestionar el fenómeno, que existen equipos de docentes que superan los escollos y convierten situaciones difíciles en éxitos notables. Así, centros en los que se podrían prever dificultades debido a la elevada presencia de alumnado de origen inmigrado, las dinámicas generadas a partir del incremento de recursos humanos, de buenas relaciones entre equipo directivo, docentes, asociaciones de madres y padres de alumnos, etc., han convertido, no sin esfuerzo, una situación que invitaba al abandono (huida de parte del alumnado, de sus familias y de docentes) en un referente para otros centros con similar "problemática». 


\subsection{La política lingüistica en educación}

A partir de la Constitución de 1978, la Administración catalana desarrolla el proceso de normalización lingüística consistente en superar la desventaja del catalán respecto al castellano en el ámbito administrativo, medios de comunicación y en el sistema escolar. Dentro de la escuela existe el Programa d'Immersió Lingüística para escolarizar a los alumnos de primer ciclo utilizando el catalán como lengua principal de comunicación. Este programa se dirige también a los niños de origen extranjero que entran en la escuela. Está claro que la situación de los alumnos que se escolarizan a una edad más avanzada es distinta y para ellos se ha creado el Programa de Incorporación Tardía - iniciado en 1996 - para la incorporación de alumnado no catalanohablante a partir del ciclo medio de enseñanza primaria. Este programa, dirigido a los alumnos que no han tenido contacto anterior con la lengua catalana, consiste en estudiar catalán desde el primer año (sin calificación); en el segundo, se les hace una evaluación especial y, en el tercero, se integran en la normalidad - aunque se mantengan criterios flexibles de evaluación -. Al mismo tiempo, se han establecido convenios de colaboración con organizaciones no gubernamentales para la organización de clases de lenguas de origen en horario extraescolar que recordemos que era una cuestión a la que se otorgaba poca relevancia en el Eix Transversal - y en los mismos centros de enseñanza impartidas por africanos con estudios universitarios y con material didáctico elaborado en origen (Colectivo IOE, 1996). Cabe señalar que esta práctica no se ha generalizado.

No podemos olvidar que en centros con mayor presencia de alumnos de origen inmigrante se realizan diversos cursos y talleres de lengua catalana que pretenden facilitar y acelerar su aprendizaje.

Según lo que podemos extraer de los datos recientes, las aulas de acogida son las máximas representantes de la línea de intervención adoptada para la acogida y acompańamiento del alumnado extranjero. El aula de acogida, de tamaño variable según el centro, tiene asignado un profesor, el tutor del aula, que recibe formación y asesoramiento desde los equipos LIC y que tiene como principal objetivo incorporar al aula ordinaria al alumnado no conocedor de alguna de las lenguas oficiales. Eso sí, el alumnado no siempre se encuentra en esta aula sino que hay materias para las que este conocimiento lingüístico no es tan esencial (inglés, educación física, música ...), en las cuales el alumnado se halla en el aula ordinaria. Para ello es muy necesaria la coordinación entre el tutor del aula de acogida y la del tutor del grupo clase puesto que deben valorar conjuntamente los progresos de cada alumno y decidir cuándo se incorporan, totalmente, a las aulas ordinarias.

La nueva Llei d'Educació de Catalunya del 17 de julio de 2009 mantiene la dirección tomada hasta el momento ya que en su artículo 10 se desarrolla el 
derecho y el deber a conocer las lenguas oficiales y, concretamente, el catalán (que, como índica el artículo 11, se trata de la lengua vehicular y de aprendizaje de Cataluña). Así, las actividades educativas (las orales y las escritas), el material didáctico, los libros de texto, las actividades de evaluación de las áreas, las materias y los módulos del currículum deben estar escritos normalmente en catalán, a excepción de las materias de lengua y literatura castellana y extranjera. Como se desprende de lo anterior, en Cataluña no existe una doble o triple red educativa por motivo lingüístico - como sucede, por ejemplo, en Quebec o en el País Vasco español -, sino que se trata de un sistema educativo único y del que, a menudo, políticamente se ha destacado lo beneficioso que resulta para la cohesión social y la cultura e identidad de Cataluña.

\subsection{El profesorado: formación y actitudes}

La formación inicial de los docentes en el campo de la diversidad cultural, impartida en las Escuelas Normales y, hoy en día, en las Facultades de Ciencias de la Educación (a través de materias obligatorias y optativas que profundizan en el análisis y la intervención en contextos multiculturales) ha sido más bien poca a lo largo de los años. En ocasiones se trataba el tema en la materia de sociología de la educación o en optativas relacionadas con la investigación realizada por los docentes pero lo más habitual era no considerar que fuera un tema prioritario, sobre todo porque esa realidad no estaba presente en Espańa. Eso sí, a medida que la inmigración y los discursos multiculturales e interculturales fueron apareciendo, a pesar de las limitaciones (Jordán, 1995), esta temática fue ocupando un mayor protagonismo en la formación de los futuros docentes. De hecho, encontramos un interés creciente por estos temas en la formación inicial y una eclosión de oferta formativa en cuanto a formación continua, una situación que no se daba años atrás. La actualidad del fenómeno de la inmigración y las minorías étnicas y la necesidad de trabajar con estos colectivos, se ha situado en el centro de interés de mucho profesorado y también del conjunto de la sociedad. Esto no significa que todo el profesorado reciba esta formación y que toda la formación que se imparte sea la idónea, al contrario, a menudo peca de excesivamente teórica y alejada de la práctica cotidiana, dos características que suscitan las críticas del profesorado que la recibe.

El estudio de A. Jordán (1995) afirmaba que, en Cataluña, los esfuerzos para llevar a cabo una adecuada formación inicial y continua del profesorado en este campo son escasos, esporádicos y fragmentarios, entre otras cosas por la falta de una legislación específica al respecto. Pero actualmente, además de la amplia oferta de cursos, seminarios y jornadas organizados desde múl- 
tiples instancias, el Departament d'Educació, dentro del plan de formación del profesorado, con el objetivo de mejorar la educación intercultural en los centros, también realiza una serie de actividades formativas: cursos de educación intercultural en las zonas con más presencia de inmigrantes; formación específica de los equipos LIC, sensibilización, etc. (Castella, 2001). A pesar de esto, nos resulta evidente que todavía hay que dedicar importantes esfuerzos a la formación del profesorado, ya que la inmensa mayoría de ellos ha recibido una formación inicial que no tenía en cuenta que el sistema educativo de Cataluña acoge alumnado con diferentes orígenes lingüísticos y culturales (aunque hace tiempo que convivimos con los gitanos).

Otro de los temas de interés es la actitud de los docentes ante la diversidad, pero sobre todo ante los recientes cambios discursivos. Años atrás (Garreta, 2003) evidenciamos que el discurso intercultural, que en general se cree que ha de ser un referente en todas las escuelas, se acostumbra a entender más o menos en función, principalmente, de la formación recibida sobre el tema, aunque esto no implica que posteriormente se sepa trasladar al aula. Como ya se ha indicado, la escasa formación inicial de los docentes y la no muy frecuente educación permanente del profesorado contribuyen a alimentar la fractura existente entre discurso y práctica. Tampoco ayuda mucho la sensación que queda en algunos docentes que, incluso después de haber realizado formación específica, siguen diciendo que no tienen claro cómo aplicarla. Si la formación impartida peca de excesivamente teórica (ya que, en general, los docentes sitúan por delante el conocimiento de estrategias y formas concretas de intervenir en contextos multiculturales), las orientaciones, usualmente generalistas, dadas en los documentos de la Administración, tampoco contribuyen a mejorar la valoración de la situación. Además, en la práctica cotidiana, los docentes que realizan intervenciones en el aula no son muchos y, cuando lo hacen, no siempre se adecuan al modelo intercultural. En demasiados casos se trata de prácticas puntuales, tranquilizadoras, que permiten aparcar el tema hasta el curso siguiente (modelo aditivo) y que se llevan a cabo en aulas que tienen este problema.

Profundizando en la cuestión a partir de la encuesta realizada a docentes de Cataluña, confeccionamos una tipología (utilizando el análisis multivariado de cluster) que permitiera la detección de las actitudes de los docentes para, posteriormente, relacionarlas con las prácticas intentando superar los límites de la visión lineal de un único vector. En síntesis, diferenciamos entre los docentes que tienen un discurso positivo hacia la interculturalidad (el $12,5 \%$ muy positivo y, el $37,5 \%$ positivo) y los que lo tienen negativo (33\% negativo y $15 \%$ muy negativo), manteniéndose el resto en un punto medio. Cabe destacar cómo la experiencia vivida con este tipo de alumnado es la más definitoria de los discursos que aparecen ya que son los que se sitúan 
en los extremos (discursos más viscerales y arraigados en lo positivo o en lo negativo), los que se diferencian por la presencia o casi ausencia de minorías. El discurso más positivo - e intercultural - es el de aquellos docentes que tienen más alumnado gitano y/o de origen extranjero en el aula mientras que, el más negativo, se caracteriza por surgir de la situación contraria. Parece pues que los discursos arraigan, pero ¿son reales?, ¿se traducen en prácticas? Según nuestros datos, no siempre los discursos más positivos e interculturales se traducen en prácticas interculturales. Así, por ejemplo, es paradójico que los profesores que tienen un discurso más positivo sean los que más dicen que no es necesario hacer nada, aun cuando tienen diversidad cultural en el aula, y que sean también los que en mayor número, comparativamente, sólo realizan explicaciones puntuales de la cultura del alumnado «diferente culturalmente». Por otra parte, sí es cierto que los que muestran una actitud más negativa son los que menos actuaciones realizan en aras de la educación intercultural. En este caso sí podemos decir que discurso y práctica se relacionan ya que los docentes creen que se trata de temas que deben tener en cuenta los que tienen esa realidad en el aula. Finalmente, tenemos aquellos que, a pesar de tener una actitud positiva, no elaboran discursos extremos, son los que lo están enfocando la enseñanza de una forma más intercultural. Las situaciones detectadas, en las que hemos ido profundizando en estudios posteriores (Garreta et al., 2007 y Garreta, Llevot, \& Bernad, 2008), ponen de manifiesto que no todos los discursos de respeto y valoración de la diversidad cultural incorporan intervenciones y que las resistencias son mayores de las esperadas.

\subsection{Problemas y desafios ante la diversidad}

Sintetizando, a partir de lo descrito y valorando los importantes avances realizados en el poco tiempo transcurrido desde que la presencia de extranjeros es una realidad en las aulas de Cataluña, destacaríamos como principales y prioritarias líneas de trabajo para el futuro.

La adecuación de la práctica cotidiana al discurso teórico intercultural, para lo cual parece necesario potenciar el trabajo realizado desde los equipos LIC y favorecer aún más la innovación educativa que están realizando los centros escolares para trabajar la diversidad cultural (tengan o no alumnado extranjero ya que, según el discurso intercultural dominante, todos los centros deben preparar a los alumnos para la sociedad diversa en la que vivimos).

La adecuación de los recursos humanos y materiales al número de extranjeros, especialmente en la red pública. Mientras que a mediados de los noventa se registró un descenso de la matrícula por el efecto de la baja natalidad y el cierre o reorganización de centros escolares, la llegada progresiva de 
inmigración, el aumento de la natalidad y el incremento de horas lectivas (la llamada «sexta hora») han comportado que no se disponga de aulas y docentes suficientes y que exista la sensación de que el fenómeno de la inmigración (al que se atribuye principalmente la responsabilidad de este desajuste) ha superado al sistema educativo. Por ello parece imprescindible una mayor dotación para hacer frente con garantía de éxito a esta realidad escolar.

La mejora de la formación docente: dado que el discurso intercultural descansa en gran parte en manos de los docentes y que la formación inicial y continua ha sido históricamente insuficiente, aunque haya mejorado en los últimos años, consideramos prioritario dar formación específica a todo el profesorado, tenga o no diversidad cultural en sus aulas, ya que la educación intercultural en el modelo catalán está pensada para preparar al alumnado tanto para una actual como futura convivencia en una sociedad multicultural.

La mejora de la acogida del alumnado (y de sus familias), de los procesos de incorporación tardía y de las políticas de continuidad en los niveles no obligatorios del alumnado extranjero. A pesar del trabajo realizado, la incorporación de este alumnado, especialmente el que llega una vez iniciado el curso, no es fácil y tampoco lo es que tengan oportunidades para continuar más allá de los niveles escolares obligatorios (Serra \& Palaudàrias, 2008), por ello creemos que es clave mejorar esta atención pero sobre todo diseñar políticas que garanticen la continuidad del alumnado extranjero en los niveles educativos superiores.

\section{CASO PRÁCTICO: EL CENTRO ESCOLAR DE INFANTIL Y PRIMARIA «LA SENYERA» ${ }^{9}$}

\subsection{La diversidad cultural en "La Senyera»: legislación e impacto}

El centro se encuentra en una población de poco menos de 150.000 habitantes. Es un centro de enseñanza público de Educación Infantil y Primaria (CEIP) construido a mediados de los ańos ochenta que cuenta con cerca

9 El centro escogido, con nombre ficticio, no responde a lo «normal» en la escuela catalana. Más bien es un centro con una problemática mucho más elevada en comparación con la media pero que evidencia la situación de concentración del alumnado inmigrado en algunos centros escolares así como las problemáticas específicas derivadas de la misma. Forma parte de un estudio de casos en centros de primaria de Catalunya para analizar la relación familia-escuela, proyecto que finalizó en 2010, financiado por la Fundación Jaume Bofill y dirigido por el Jordi Garreta de la Universidad de Lleida (no publicado). 
de 250 alumnos y en el que trabajan 25 profesionales. En las clases la ratio acostumbra a ser de 25 alumnos, aunque en algún caso puntual también hallamos aulas con 27 y 28; por el contrario, en algún curso elevado de primaria existen vacantes.

Una característica destacable es la gran movilidad del alumnado y la matrícula viva durante el curso, es decir, alumnado que se da de alta o de baja durante el mismo. Se trata de una escuela que en los últimos años era poco solicitada por las familias autóctonas y que poco a poco se ha ido convirtiendo en un centro con elevada presencia de familias extranjeras. En el curso 2008/2009 el 70\% eran familias extranjeras y, sobre todo, se trataba de inmigrantes marroquíes, argelinos, gambianos, brasileños, ecuatorianos y rumanos, en este orden. El origen socioeconómico de las familias, tanto autóctonas como inmigradas, era bajo.

El marco legislativo que gobierna el centro en el tema de la diversidad cultural y, por extensión, del alumnado de origen extranjero, es el anteriormente citado y, por tanto, debe desarrollar aquellas actuaciones previstas para un centro con importante presencia de alumnado extranjero. Eso sí, su aplicación práctica se adapta a la realidad concreta.

Para acercarnos a ella hemos realizado una etnografía durante dos meses y entrevistas en profundidad a seis docentes. Todo ello nos ha permitido constatar que tienen experiencia desde hace años con alumnado extranjero y que los docentes que se incorporan lo hacen conociendo la situación del centro, la línea de trabajo y la necesidad de dar una atención lo más personalizada posible. El profesorado tiene la sensación de que se trabaja mucho, para algunos incluso es una sobrecarga que no tienen claro que puedan soportar durante mucho tiempo. Esta carga comporta que existan tensiones y que se perciba la existencia de dos grupos entre los docentes: el equipo directivo y los docentes que siguen su proyecto y los que, por unos u otros motivos, no creen que sea la línea adecuada. Eso sí, todos piensan que necesitarían más recursos humanos y materiales para implementar un proyecto en un centro con esta elevada diversidad. Además, el hecho de que la movilidad docente sea alta - el curso 2007/2008 fueron substituidos ocho docentes -, no ayuda. El equipo directivo está intentando motivar al profesorado para potenciar los resultados académicos y apoya a la Asociación de Madres y Padres de Alumnos (AMPA) para conseguir una renovación de sus cargos y la implicación de las familias extranjeras.

En la escuela se trabaja la interculturalidad desde un punto de vista aditivo, es decir, se realizan actividades puntuales en algún momento del año (por ejemplo, la semana intercultural o la presencia de algún padre o madre extranjero que presenta su experiencia en alguna de las aulas) pero el currículum se mantiene como años atrás. La argumentación para no ir más allá 
es el exceso de trabajo, que supera a los docentes, además de la dificultad para desarrollar un proyecto de centro por la elevada movilidad del profesorado. También es cierto que se está trabajando en el frente de la relación familia-escuela ya que en los últimos ańos esta cuestión ha pasado a ser una de las prioridades. Se realiza un esfuerzo importante para incorporar familias, especialmente extranjeras, a la Asociación de Madres y Padres de Alumnos y en los órganos de decisión en los que los progenitores tienen representación. Aunque no sin resistencia por parte de las familias autóctonas y de las extranjeras (unas, por interés de seguir manteniendo su elevada representación y, otras, por desconocimiento del motivo para implicarse y de cómo deberían hacerlo), se ha ido avanzando en la representación de la multiculturalidad del centro en la AMPA y en los órganos de dirección y/o consulta.

En el centro existe un plan de acogida. Se trata de una respuesta educativa justificada sobre todo por la continua llegada de alumnado extranjero, que se produce durante todo el curso. El objetivo es, ante todo, que el alumnado y sus familias perciban que se les acoge y se les reconoce su protagonismo y que se valore su presencia como enriquecedora para toda la comunidad escolar. Para ello han elaborado distintas fases y materiales.

Cuando el alumno llega por primera vez al centro para solicitar plaza, en secretaría se le entregan unas instancias traducidas, así como una hoja informativa en la que puede ver en su idioma qué documentos necesita y dónde puede encontrarlos, además de unos trípticos sobre el sistema educativo. Ambos materiales se hallan a su disposición traducidos en varias lenguas (catalán, castellano, chino, árabe, francés ...). También existe la posibilidad de recurrir a un traductor lingüístico y/o mediador intercultural del Departament d'Educació para comunicarse, puntualmente, con las familias.

Si hay plaza en el centro y el alumno presenta la documentación pertinente, volverá al colegio y toda la familia será recibida por un maestro de guardia de acogida y el equipo directivo o alguno de sus miembros, que le explicarán, con la ayuda de algún alumno o padre o madre traductor natural, las líneas generales de funcionamiento del centro, así como la necesidad de una futura y mutua colaboración (para ello establecerán un plan de reuniones para el curso escolar).

A continuación, una vez iniciado el curso, se realiza la acogida en el aula del alumno, al que se le presentará la forma de trabajar, las actividades que se realizarán y a sus compañeros.

La última fase de acogida se refiere a la acogida de la familia por parte del resto de la comunidad escolar. Para ello se organizan cada año Jornadas Interculturales en las que se dan a conocer las señas de identidad de cada uno de los países que colaboran con la AMPA. Las familias extranjeras son, a menudo, protagonistas de la exposición y los talleres que se realizan. 


\subsection{Medidas especificas en materia lingüistica}

Como se ha avanzado en el apartado anterior, las actuaciones lingüísticas realizadas por el centro son comunes a muchos otros de Cataluña. Así, dentro de la acogida del alumnado (y de la relación de la escuela con las familias) se ha optado, cuando la situación lo ha requerido y nunca de forma permanente, por utilizar el servicio de un traductor así como por la traducción de algunos documentos básicos (por ejemplo, un tríptico en el que se explica el funcionamiento y los objetivos de la escuela). Aunque esto está muy bien valorado, se cree que debe ser una medida provisional hasta que las familias puedan comunicarse directamente con el profesorado (situación óptima). Además, también se utiliza la mediación natural, es decir, que otras familias o alumnos conocedores de una lengua ayuden puntualmente en esta comunicación entre escuela y familia. En este caso son conscientes de que esto comporta problemas, dado que implica la incorporación de una tercera persona que no tiene por qué generar confianza en la comunicación. De modo que, para cuestiones que pueden ser consideradas delicadas, se prescinde de esta opción.

La escuela cuenta con un aula de acogida y con el profesor-tutor del aula correspondiente, que tiene como función principal la incorporación, lo más rápido posible, al aula ordinaria del alumnado que no conoce el catalán y el castellano. Esta aula está bien valorada por todos los docentes ya que se ve como la única forma de que, en el menor tiempo posible, el alumno comprenda y pueda comunicarse en catalán y pase al aula ordinaria. A pesar de esta buena valoración global, también es cierto que el hecho de que exista únicamente un aula llega a desbordar al profesor responsable de la misma, puesto que la llegada de alumnado a lo largo del curso es constante y, en ocasiones, se produce de forma numerosa. En este sentido, se reconoce que en más de una ocasión se debe avanzar la entrada en el aula ordinaria de algún alumno porque llegan otros con más necesidades. Este es uno de los temas en los que se evidencia la necesidad de contar con más recursos, especialmente humanos.

\subsection{El claustro de profesores}

Respondiendo a la línea general dibujada y a pesar de los cambios más recientes, la formación de los docentes en lo referente a la diversidad cultural es limitada. No obstante, hay que destacar que una parte de ellos (los que decidieron quedarse y afrontar el cambio vivido por el centro en cuanto a perfil de su alumnado y familias o los más jóvenes y que han creído en el proyecto 
del equipo directivo), mediante la formación de equipos de trabajo, ha ido desarrollando estrategias específicas, a menudo relacionadas con el entorno (a pesar de no existir un Plan de Entorno) y con la mayor implicación de las familias en la escolarización de los hijos. De esta forma, la innovación educativa realizada por estos profesionales a partir de los referentes abstractos de la Administración está generando iniciativas interesantes y exitosas que a menudo son difundidas con el nombre de "buenas prácticas» y copiadas o adaptadas por otros centros escolares. Este hecho no hace más que indicar la necesidad que hay de contar con estrategias de intervención y pone de manifiesto que los docentes, con su quehacer cotidiano, con sus experiencias, están llenando de contenido los discursos de los políticos y de la Administración.

Entre los docentes, una vez superado el choque por el cambio que supuso el incremento tan notable de extranjeros en pocos años, observamos diferentes preocupaciones, entre las que destacaríamos la citada sobrecarga de trabajo, ya que las ratios son elevadas (y más cuando existe matrícula viva e incorporación tardía) y no han estado acompañadas de un incremento de recursos humanos y económicos. Otra preocupación de los docentes y un hecho que, en parte, ya tienen asumido es que el alumnado extranjero se concentre en unos determinados centros (en los suyos, concretamente), lo cual se percibe como otro obstáculo para la adaptación de este alumnado ya que, para muchos, los extranjeros tienden a agruparse y a mantener sus costumbres mientras que ellos creen que una mayor dispersión del colectivo podría favorecer su integración. Desde este punto de vista, la adaptación se produciría de forma espontánea o, al menos, se considera que así sería. Otro tema sobre el cual todo el profesorado manifiesta preocupación es la igualdad de oportunidades entre los niños y las niñas ya que muchas familias marroquíes presentan actitudes discriminatorias hacia las segundas. De acuerdo con su apreciación, esta discriminación se relaciona con la cultura y la religión musulmana, que justifican la subordinación de las mujeres. El Islam se sitúa en el punto de mira de las problemáticas y es una de las que los docentes creen que es más difícil de resolver. Una parte importante de ellos considera que, en el fondo, el problema principal es que algunas familias extranjeras, especialmente las marroquíes, no tienen intención de integrarse en la sociedad de acogida y, por tanto, se aferran a sus costumbres. Eso sí, esta no es una opinión unánime ya que hay algunos docentes que creen que no es correcto generalizar y que señalan que existen diferentes actitudes entre las familias. Lo que sí es cierto es que entre los docentes existen imágenes de la alteridad (a menudo los musulmanes son los menos valorados y se cree que son los más resistentes a acomodarse a la sociedad y a la escuela) que influyen en las relaciones cotidianas y las expectativas que generan familias y alumnado (Garreta, Llevot, \& Bernad, 2009). 


\subsection{Algunas propuestas ...}

Sintéticamente, observamos que en el centro estudiado, dada la realidad de familias y alumnado que tiene, y que parece que una parte de los docentes ha asumido como normal pero otra parte no, el principal problema es la consolidación de un equipo de trabajo compacto (sin divisiones internas) y que apueste por llevar a cabo un proyecto de centro.

Otros aspectos a considerar son el fenómeno de la incorporación tardía que debe atenderse con protocolos específicos de actuación así como la procedencia del alumnado inmigrante que comportaría la estandarización de algunas necesidades básicas con descripciones del sistema educativo de origen y el posible desajuste con el nuestro.

La división existente entre el profesorado y la movilidad importante de los docentes hace difícil su materialización. A pesar de ello, es cierto que el equipo directivo cree en las posibilidades del centro y de sus familias y alumnado por lo que dedica ingentes esfuerzos a dinamizar este trabajo, con lo que representa de sensación de sobrecarga entre los docentes (más bien llevada por los que comparten el proyecto en comparación con los más reticentes). Esta sensación creen que se podría reducir con un incremento de los recursos humanos (más docentes y otra aula de acogida) y materiales y con el mayor reconocimiento del trabajo realizado (muy a menudo se habla de que a final de mes todos cobran lo mismo, los que están en centros como éste y los que tienen condiciones de trabajo más cómodas).

Otro de los frentes en los que trabajan (y en el que aseguran que todavía queda mucho por hacer) es en el aumento de la implicación de las familias, especialmente las extranjeras, en los órganos de gobierno y en la AMPA de la escuela. Esta mayor implicación también la relacionan con el trabajo de las actitudes y las expectativas de estas familias respecto a la educación. Proponemos que todas las lenguas familiares se vean respetadas y reconocidas para percibirlas con toda su dignidad y como un factor enriquecedor.

También son conscientes de la necesidad de mejorar su formación para trabajar en un contexto tan diverso culturalmente. En este sentido, entendemos que es necesario trabajar también las imágenes de la alteridad que tienen estos docentes ya que afectan directamente a la dinámica cotidiana de los centros (etiquetaje de familias y alumnado). Para ello apuntamos que el claustro de profesores tenga un plan de formación permanente (en todas sus dimensiones: curricular, institucional, metodológica y organizativa) y que promuevan la relación e intercambio que otros entornos, religiones, países (especialmente, con los de origen de su propio alumnado).

Por último, otras medidas serían la creación de una página web con información, una red de asesores en educación intercultural, la creación de 
la figura del mediador intercultural como recurso permanente, la concesión de ayudas y recursos de compensación educativa (proyectos), los premios de materiales didácticos, la elaboración de una guía de recursos didácticos y su difusión a través de Internet.

\section{REFLEXIONES FINALES: RELACIÓN RETÓRICA-REALIDAD}

La mayor dificultad encontrada ha sido que el fenómeno de la inmigración ha superado las mayores expectativas de crecimiento demográfico por inmigración que se podían haber realizado y que tampoco se previó ni su impacto en las escuelas ni la diversificación de los orígenes, que han hecho más complejas todas las intervenciones.

Una segunda cuestión a tener presente es la formación de los docentes (inicial y continua) que, históricamente, no tenía en cuenta la diversidad cultural y la intervención respetuosa para con ella (a pesar de la existencia de gitanos y Comunidades Autónomas con lengua y cultura propias como Cataluña, País Vasco y Galicia) y que sólo recientemente se ha potenciado en las Facultades de Educación y en la formación continua. Los docentes que tenían alumnado extranjero a menudo han buscado recursos formativos o han innovado para dotar de prácticas de centro y aula al discurso de la interculturalidad. De hecho, esta desproporción entre el discurso y la praxis es una de las principales debilidades de nuestro sistema pero la innovación realizada por una parte de los docentes las está superando poco a poco.

En tercer lugar, más allá de la necesaria dotación de recursos (humanos y materiales) a los centros que asumen mayor número de este alumnado (que, en parte, ya se realiza aunque no parece suficiente), los trabajos consultados nos indican que la presión existente comporta en ocasiones el diseño de actuaciones temporalmente segregacionistas o la aplicación ineficiente de determinadas medidas por no poderse desarrollar plenamente (por ejemplo, la estancia temporal en el aula de acogida). Esto contribuye a la sensación de que en las aulas el fenómeno no se acaba de gestionar bien.

En los últimos meses, con el cambio de gobierno a CIU, la nueva consejera de Educación se ha mostrado partidaria de realizar algunos cambios (impulsar el catalán como lengua vehicular, la inmersión en entornos lingüísticos multiculturales ...) insistiendo en las políticas de libertad de elección del centro educativo (la creación de dos subdirecciones generales, una para la red pública y otra para la privada-concertada ...) acciones que vuelven a enfrentar a la comunidad educativa. 
A pesar de todo lo dicho, la inesperada evolución e impacto de la inmigración en las aulas ha obtenido respuesta desde la Administración catalana y se ha ido evolucionando, desde discursos más asimiladores y compensatorios, a otro más intercultural que se centra en la búsqueda de la cohesión social como se está realizando en otros países (UNESCO, 2010). Es cierto que aún existen desajustes entre las necesidades de los centros escolares que cuentan con un número importante de extranjeros y los recursos que se destinan pero también lo es que, en poco más de diez años, se ha realizado un relevante avance tanto en el discurso como en la práctica.

\section{REFERENCIAS BIBLIOGRÁFICAS}

Banks, J. A. (1986). Race, ethnicity and shooling in the United States: Past, present and future. En J. A. Banks \& J. Lynch (Eds.), Multicultural education in Western societies (pp. 30-50). New York: Praeger.

Bartolomé, M. (1997). Minorías étnicas, inmigración y educación multicultural. El estado de la cuestión en Cataluña. En M. Bartolomé (Coord.), Diagnóstico a la escuela multicultural (pp. 27-81). Barcelona: Cedecs.

Castella, E. (2001). Les politiques escolars adreçades a l'alumnat d'origen immigrant, Barcelona, Trobada de Treball Catalunya - Quebec, 24, 25 y 26 de abril (no publicado).

Centro de Investigación y Documentación Educativa (2007). Boletín CIDE de Temas educativos. El alumnado extranjero en el sistema educativo español (1995-2006). Madrid: CIDE.

Colectivo IOÉ (1996). La educación intercultural a prueba. Hijos de inmigrantes marroquies en la escuela. Granada: Laboratorio de Estudios Interculturales.

Crea (2010). Gitanos: de los mercadillos a la escuela y del instituto al futuro. Madrid: Ministerio de Educación, Colección Estudios Creade, núm. 6.

Demba, P., \& Garreta, J. (2012). Les migrations africaines vers l'Europe. Entre mutations et adaptation des acteurs sénégalais. Dakar: REMIGRAF-IFAN-ASE Lleida.

Departament de Benestar Social (1993). Pla Interdepartamental d'Immigració 19932000. Barcelona: Generalitat de Catalunya.

Departament d'Ensenyament (1992a). Currículum. Educació primària. Barcelona: Generalitat de Catalunya.

Departament d'Ensenyament (1992b). Educació secundària obligatòria. Ordenació Curricular. Barcelona: Generalitat de Catalunya.

Departament d'Ensenyament (1996). Orientacions per al desplegament del curriculum. Educació intercultural. Barcelona: Generalitat de Catalunya. 
Departament d'Ensenyament (2002). Dades de l'inici del curs 2002-2003. Dossier de Premsa. Barcelona: Generalitat de Catalunya (no publicado).

Departament d'Ensenyament (2010). Servei d'indicadors i Estadística. Barcelona: Generalitat de Catalunya.

García Garrido, J. L. (2004). Fenómenos migratorios, multiculturalidad y educación, perspectiva comparada. Revista Bordón (Madrid), 56, 129-142.

Garreta, J. (2003). El espejismo intercultural. La escuela de Cataluña ante la diversidad cultural. Madrid: Centro de Investigación y Documentación Educativa.

Garreta, J. (2006). Ethnic minorities in the Spanish and Catalan educational systems: From exclusion to intercultural education. International Journal of Intercultural Relations (Oxford), 30(2), 261-279.

Garreta, J. (2007). Escuela, familia de origen inmigrante y participación. Revista de Educación (Madrid), 354, 133-145.

Garreta, J. (2009). Sociedad multicultural e integración de los inmigrantes en Cataluña: discursos y prácticas. Lleida: Universitat de Lleida.

Garreta, J., Llevot, N., \& Bernad, O. (2009). La relació família d'origen immigrant i escola primària de Catalunya. Lleida: Fundació Jaume Bofill y Universitat de Lleida (no publicado).

Garreta, J., Samper, L., Mayoral, D., Llevot, N., Molina, F., Lapresta, C., Serra, C., Palaudàrias, J. M., Notario, G., Salinas, E., Monclús, S., \& Creixell, N. (2007). La relació familia d'origen immigrat i escola: l'Islam en els centres educatius de Catalunya. Lleida: Universitat de Lleida (Proyecto ARIE2005) (no publicado).

Jordán, A. (1995). La escuela multicultural. Un reto para el profesorado. Barcelona: Paidós.

Lippke, W., \& Schulz, D. (2012). Migration und sprachliche. Integration als schulädagogische. Herausforderung an Europa. Leipziger: Universitätsverlag.

Llevot, N. (2005). Del programa d'Educació Compensatòria al nou Pla per a la Llengua i la Cohesió Social. Papers. Revista de Sociología (Barcelona), 78, 197-214.

Llevot, N., \& Garreta, J. (2012). Schüler aus Migrantenfamilien und die Schule in Katalonien. Politische Rhetorik und die Realität der Schule. En W. Lippke \& D. Schulz, Migration und sprachliche. Integration als schulädagogische. Herausforderung an Europa (pp. 99-127). Leipziger: Universitätsverlag.

Martínez Usarralde, M. J. (Coord.). (2010). Y para muestra ... Políticas educativas de inmigración y modelos de escuela que practian la interculturalidad. Revista Española de Educación Comparada, 18, 371-373.

Observatori Permanent de la Immigració, Universitat de Lleida i Diputació. http:// www.opi.udl.cat/opi/; http://www.opi.udl.cat/opi/ (consultado el 2 de febrero de 2013).

Palaudàrias, J. M. (1998). Análisis de la política educativa en la escolarización de las minorías culturales en Catalunya. En X. Besalú, G. Campani, \& J. M. Palau- 
dàrias (Comp.), La educación intercultural en Europa (pp. 171-180). Barcelona: Pomares-Corredor.

Pascual, J. (1992). La socialització dels fills de magrebins a Osona. En J. L. Alegret et al., Sobre interculturalitat (pp. 139-146). Girona: Fundació Sergi.

Samper, L., Garreta, J., \& Llevot, N. (2001). Les enjeux de la diversité culturelle dans l'école catalane (Espagne). Revue des Sciences de l'Éducation de la Université de Montreal (Quebec), 3, 543-568.

Secretariado Nacional Gitano (1982). La escuela "puente» para niños gitanos. Madrid: Secretariado Nacional Gitano.

Serra, C., \& Palaudàrias, J. M. (2008). Estudi dels processos de continuïtat $i$ discontinuïtat en el pas de l'escolarització obligatòria a la postobligtòria entre els alumnes membres de families immigrades. Barcelona: Fundació Jaume Bofill. http://www.migracat.cat.

UNESCO (2010). Informe Mundial de la UNESCO. Invertir en la diversidad cultural y el diálogo intercultural. Disponible en http://unesdoc.unesco.org/images/ 0018/0018/001847/184755s.pdf; http://unesdoc.unesco.org/images/0018/ 0018/001847/184755s.pdf (consultado el 5 de marzo de 2011).

\section{Riassunto}

C’è stata una notevole evoluzione in materia di immigrazione negli ultimi dieci anni, con evidenti effetti sul sistema educativo. Tale incremento, concentrato soprattutto nel settore pubblico, ha rappresentato una grave sfida per l'amministrazione e le scuole. Nonostante gli sforzi fatti nella progettazione delle politiche, dei piani di emergenza e di allocazione delle risorse, $i$ risultati possono ancora essere migliorati. In Catalogna, dopo un periodo di osservazione, l'accento è stato posto sull'organizzazione dei vari livelli amministrativi per realizzare un intervento efficace. In pratica, per quanto riguarda gli studenti stranieri, questo ha significato l'adozione di politiche compensative incentrate sulla coesione sociale e la multiculturalità. Questo articolo costituisce una rassegna delle politiche educative condotte in Catalogna, con una specifica analisi delle pratiche multiculturali applicate all'istruzione in una scuola elementare. Si tratta di una relazione sulle politiche di immigrazione in materia di istruzione, con esempi di scuole che applicano la comunicazione interculturale in quattro regioni della Spagna (cfr. Martinez Usarralde, 2010).

Parole chiave: Catalogna, Coesione sociale, Immigrazione, Multiculturalismo, Scuola. 